\title{
A Tomada de Decisão Empresarial em Finanças: Aspectos Epistemológicos e Paradigmáticos
}

\section{Business Decision-making in Finance: Epistemological and Paradigmatic Aspects}

\author{
Matheus da Costa Gomes \\ Mauricio Ribeiro do Valle
}

Este caso de ensino fornece a possibilidade de discussão sobre questões epistemológicas e paradigmáticas em Finanças, sobretudo quanto às influências cognitivas, sociais e emocionais observadas sobre a tomada de decisão dos indivíduos - campo de estudo das Finanças Comportamentais. $O$ presente caso fictício exemplifica como as crenças, emoções e sentimentos do gestor podem influenciar suas decisões e, consequentemente, impactar o desempenho de seu negócio. Inicialmente, o caso de sucesso do Sr. Batista é apresentado e serve para elucidar o que vem depois dele: revisão da literatura envolvendo a tomada de decisão financeira, questões para reflexão, discussão e considerações finais. Ao apresentar aspectos contemporâneos da discussão paradigmática em Finanças e ao fornecer de forma elucidativa ideias e base teórica para pesquisadores, alunos e demais indivíduos interessados na investigação teórica e prática de assuntos da área, este caso de ensino contribui com a formação e o desenvolvimento de senso crítico de profissionais de finanças, pesquisadores, estudantes de pós-graduação e estudantes de graduação em nível avançado.

Palavras-chave: Epistemologia. Paradigma. Finanças Comportamentais. Finanças Corporativas. Tomada de Decisão Financeira.

This teaching case provides the possibility for discussion on epistemological and paradigmatic issues in finance. It deals mainly with the cognitive, social, and emotional influences observed on the decision making of individuals - Behavioral Finance's study field. This fictitious case exemplifies how a manager's beliefs, emotions, and feelings can influence his decisions and, consequently, impact his business' performance. Initially, Mr. Batista's success story is presented and serves to elucidate what comes after that: a literature review involving financial decision making, issues for reflection, discussion, and concluding remarks. In submitting contemporary aspects of the paradigmatic debate on finance and providing
Recebido em: 26/12/2018 Aprovado em: 30/04/2019
Matheus da Costa Gomes (iD matheusgomes@usp.br

Mestre em Controladoria e Contabilidade - Universidade de São Paulo

Master in Controllership and Accounting

- University of São Paulo

Universidade de São Paulo

Ribeirão Preto/SP - Brasil

Mauricio Ribeiro do Valle (D)

marvalle@usp.br

Livre docente da FEARP - Universidade de São Paulo

Full Professor - FEARP - University of

São Paulo

Universidade de São Paulo

Ribeirão Preto/SP - Brasil 
enlightening ideas and theoretical basis for researchers, students and other individuals interested in academic research and practical issues in the area, this teaching case contributes to the critical sense formation and development of finance professionals, researchers, graduate students, and advanced undergraduate students.

Keywords: Epistemology. Paradigm. Behavioral Finance. Corporate Finance. Financial Decision Making.

\section{Introdução}

Rotulam-se finanças corporativas tradicionais aquelas teorias que derivam do princípio de maximizar o valor da empresa (ARDALAN, 2017). Para elas, as empresas buscam sempre o lucro, por meio de uma análise custo-benefício, e o indivíduo é representado pelo homo economicus - sujeito maximizador racional de utilidade (ARDALAN, 2008; BURRELL; MORGAN, 1979). Em contraste, os sujeitos tomadores de decisões financeiras que agem sob os pressupostos das finanças comportamentais não são o tempo todo indivíduos maximizadores de riqueza e algumas de suas decisões podem ser consideradas ex-post como não racionais (THALER, 2018; ÁVILA et al., 2016; BAKER; RICCIARDI, 2014).

Existem várias situações no complexo mundo das decisões financeiras para as quais é preciso recorrer a explicações fora do padrão ou não racionais do ponto de vista das finanças corporativas tradicionais. Essas situações podem ter explicações no comportamento dos agentes econômicos tomadores de decisões. Por exemplo, por que um gestor deixaria de captar recursos de terceiros que seriam utilizados para investir em projetos com valor presente líquido positivo? A resposta é que esse gestor pode estar sendo influenciado pela sua disposição a assumir riscos, que, por sua vez, traduz-se em assumir mais ou menos dívidas, ou, ainda, os projetos de investimento podem estar sendo subestimados devido à aversão a perdas ou falta de confiança do gestor.

A verdade é que os vieses comportamentais influenciam as decisões financeiras dos gestores (MALAQUIAS; MAMEDE, 2015; ROSTAMI; DEHAGHANI, 2015). Devido ao avanço trazido por pesquisadores na área de economia comportamental (behavioral economics), muitas explicações têm agora nas teorias de 
comportamento alternativas viáveis às teorias tradicionais das finanças corporativas. Embora aquelas não tenham ainda atingido o mesmo nível de desenvolvimento dessas últimas, as abordagens que consideram o indivíduo um ser multifacetado em um ambiente dinâmico e complexo são positivas e têm trazido novas ideias e contribuições para as Finanças. No Brasil, o tema ganhou relevância e vem apresentando um crescimento médio de $20 \%$ ao ano de publicações em periódicos nacionais (SILVA; SANTOS; PEREIRA, 2018). Por isso, torna-se importante apresentar e diferenciar essas duas abordagens, fazendo uma comparação crítica entre elas.

O objetivo geral deste caso de ensino é fornecer a possibilidade de discussão sobre questões epistemológicas e paradigmáticas em Finanças, sobretudo quanto às influências cognitivas, sociais e emocionais observadas sobre a tomada de decisão dos indivíduos, campo de estudo das Finanças Comportamentais. O caso tem como objetivo educacional promover reflexões a respeito da complexidade do processo de tomada de decisões financeiras no contexto empresarial. O presente caso fictício exemplifica como as crenças, emoções e sentimentos de um gestor podem influenciar suas decisões e, consequentemente, impactar o desempenho de seu negócio.

Ao apresentar aspectos contemporâneos da discussão paradigmática em Finanças e ao fornecer de forma elucidativa ideias e base teórica para pesquisadores e demais indivíduos interessados na investigação teórica e prática de assuntos da área, este caso de ensino deve ser utilizado em disciplinas de Finanças, em cursos de graduação e pós-graduação. O presente caso de ensino contribui com a formação e o desenvolvimento de senso crítico de profissionais de finanças, pesquisadores, estudantes de pós-graduação e estudantes de graduação que tenham repertório ou uma formação base sobre epistemologia ou filosofia da ciência.

Dentro de um processo de aprendizagem, o uso deste caso deve vir acompanhado de uma revisão da literatura envolvendo a tomada de decisão em Finanças. Portanto, o caso apresentado serve para elucidar o que vem depois dele: revisão da literatura contendo aspectos epistemológicos e paradigmáticos da tomada de decisão financeira, questões para reflexão, discussão e considerações finais. 


\section{O Caso de Sucesso do sr. Batista}

Com o avanço da industrialização e das preocupações quanto à segurança do trabalho, numa época onde o número de acidentes nas fábricas era grande, o até então operário de uma linha de fabricação de produtos pesados começou a fazer seus próprios sapatos para trabalhar. A partir de uma pequena fábrica no fundo de casa, o Sr. Batista passou a produzir calçados melhores do que os que ele usava para trabalhar, a fim de aguentar a árdua jornada de trabalho.

O Sr. Batista tinha conhecimentos sobre confecção de sapatos que aprendera com o avô paterno e, por meio do couro de gado da fazenda dos pais, ele desenhou e confeccionou um sapato bem resistente, com bico de ferro, para uso próprio. O chefe do Sr. Batista já cansado de afastamentos de operários machucados, principalmente por causa da frequente queda de produtos sobre as pernas e pés dos mesmos, um dia notou os sapatos do Sr. Batista e pediu para que lhe fizesse um par. Depois de testar a qualidade dos novos sapatos, simples e resistentes, o chefe convenceu o Sr. Batista a confeccionar 500 pares, para a fábrica inteira. Foi assim que o Sr. Batista decidiu deixar o trabalho na fábrica para se dedicar totalmente à confecção de sapatos.

O Sr. Batista descobriu um amor incondicional, fazer sapatos dava-Ihe uma satisfação maior do que o antigo trabalho. O Sr. Batista se sentia como uma criança, a arte de preparar o couro, cortar, costurar e moldurar, para no fim vislumbrar sapatos novos, proporcionava-Ihe uma satisfação inigualável.

No início, o negócio do Sr. Batista era como uma empresa familiar: mãe, pai e irmãos, todos ajudavam o Sr. Batista. Contudo, com o tempo, o Sr. Batista passou a receber mais e mais encomendas e isso começou a sufocá-lo, deixando-o estressado. Ele contratou pessoas e passou a delegar algumas funções. Entretanto, o Sr. Batista fazia questão de acompanhar de perto negociações com fornecedores e clientes. Ele gostava de trazer novidades tecnológicas para o negócio: de navaIhas de aço mudou para cortes a laser. No setor de montagem, ele era rigoroso ao extremo, nenhum cabedal, solado e salto passavam se não estivessem perfeitos. $A$ qualidade era uma marca do Sr. Batista e a sua novíssima linha de sapatos era um sucesso: mais casuais, para o dia-a-dia. 
Com o crescimento do negócio, aumentaram-se as obrigações formais da empresa - pessoa jurídica - e, claro, do próprio Sr. Batista. Ele não gostava muito dessas coisas e, por isso, contratava profissionais especialistas para isso. Pressionado para abrir o capital de sua empresa na bolsa de valores, a fim de captar recursos para expandir suas vendas no Brasil e, quem sabe, para outros países, o desconfiado Sr. Batista negociou ações na bolsa, porém, sem perder o controle, ele manteve a maioria das ações sob seu poder. Em pouco tempo, o Sr. Batista percebeu que fez a coisa errada, a decisão de abertura de capital fez com que ele passasse mais tempo assinando papeis e cumprindo formalidades do que trabalhando com sapatos, eram reuniões e reuniões, opiniões e sugestões de toda a parte. Em menos de um ano, o Sr. Batista comprou todas as ações que estavam no mercado pelo triplo do preço inicial, tornou-se novamente o único dono do que ele chamava de "MINHA PAIXÃO! ".

O certo é que o Sr. Batista sempre acreditou mais em suas intuições do que nos analistas/consultores que ele contratava. Uma vez vieram para ele com um papo de "maximizar o valor da empresa". A única coisa que ele queria que fosse ao máximo era a sua satisfação com os seus sapatos. Para os analistas de mercado, o Sr. Batista deveria buscar obter sempre o maior lucro possível, mas não era o que acontecia. Uma vez um banco norte-americano ofereceu ao Sr. Batista uma linha de crédito com juros mais baixos do que os usualmente cobrados em seu país, ele não aceitou porque tinha desconfiança desses "gringos" e porque já era cliente antigo do Banco $\mathrm{W}$, onde o mesmo gerente o acompanhava há décadas. O Sr. Batista dava mais valor a questão da confiança do que da análise entre custos e benefícios.

Algumas pessoas mais próximas diziam que o Sr. Batista não aceitava limitações próprias e seguia fontes não confiáveis no processo de tomada de decisão, em vez de coletar informações concretas, o que prejudicava o desempenho do seu negócio. O fato é que as decisões do Sr. Batista eram centralizadas, poucas vezes ele voltava atrás de uma decisão. Ele acreditava em seus produtos, tinha clientes antigos e fieis, gostava de se relacionar com os seus principais fornecedores, tinha muitos amigos entre seus funcionários, pois passava a maior parte do tempo no local de trabalho. Seus produtos possuíam qualidade e preços baixos; a empresa, um grande poder de barganha. Quando uma forte concorrente entrou no merca- 
do, o Sr. Batista ficou com medo de ter que fechar as portas, mas não porque havia perdido uma grande fatia do mercado e sim porque notou que seus sapatos precisavam ser melhorados. Foi quando o Sr. Batista mais trabalhou, chegando a ficar 20 horas/dia na fábrica. Nessa época, lançou novos produtos e se manteve competitivo, manteve-se feliz.

Sua empresa já recebeu várias propostas de compra. Uma delas chegou a um valor seis vezes maior do que o esperado por especialistas de mercado. O Sr. Batista não vendia nem por cem vezes mais, não havia Sr. Batista sem empresa e não haveria empresa sem o Sr. Batista. Ninguém sabia mais dela do que ele, se alguém quisesse entender melhor o seu negócio, mais valia uma conversa de 10 minutos com o Sr. Batista do que semanas analisando as demonstrações contábeis da empresa. O Sr. Batista só não trabalhava aos sábados, coisa de crença/religião. Uma vez ele deixou de fechar um lote de sapatos para exportação porque a outra parte da negociação apenas tinha o sábado para isso e, além de sábado, era também seu aniversário, nunca que o Sr. Batista tomaria alguma decisão importante nessas datas, até porque, de acordo com ele, se o destino quis assim, então não era para ser.

A empresa do Sr. Batista está aí até hoje, é uma das mais bem-sucedidas do setor de calçados e serve de benchmark para outras companhias. O Sr. Batista nunca foi à faculdade. A parte dos demonstrativos financeiros que ele mais gosta é aquela em que conta a história da empresa e deixa uma mensagem aos leitores. $O$ Sr. Batista não pensa muito no longo prazo e muito menos em descansar, apesar da idade avançada; e as coisas vão permanecer assim enquanto ele viver.

\section{A Tomada de Decisão em Finanças: Aspectos Epistemológicos e Paradigmáticos}

Epistemologia é o estudo do conhecimento que trata da natureza, extensão e construção do conhecimento, enquanto o paradigma é composto por escolhas filosóficas referente à natureza da realidade (ontologia), à construção de conhecimento (epistemologia), à natureza humana e à metodologia (BURRELL; MORGAN, 1979). Em outras palavras, paradigma representa o conjunto de escolhas ou o padrão a ser seguido de uma determinada ciência (epistemologia). 
Para compreender melhor esses conceitos, o Quadro 1 mostra as dimensões acerca das pressuposições sobre a natureza das ciências sociais, a qual as finanças estão inseridas. Classificadas de acordo com Burrell e Morgan (1979), essas quatro dimensões (ontologia, epistemologia, natureza humana e metodologia) podem ser vistas sob duas abordagens distintas: a abordagem subjetivista e a objetivista.

Quando a ontologia do lado subjetivista se caracteriza pelo nominalismo, a realidade é interpretada centrada no indivíduo, com predomínio das emoções e abstrações, sendo a realidade fruto da imaginação das pessoas. No campo ontológico objetivista, o realismo assume uma realidade externa ao indivíduo, em um mundo concreto e invariável.

O Quadro 1 também mostra que, no que tange à dimensão epistemológica, o conhecimento pode ser relativo e, portanto, não mensurável (antipositivismo), ou científico, o qual pode ser verificado e mensurado (positivismo). Na avaliação subjetivista da natureza humana, os indivíduos possuem livre-arbítrio (voluntarismo), já na avaliação objetivista, eles são determinados pelo ambiente onde estão inseridos (determinismo). A dimensão da metodologia subjetivista, a ideográfica, caracteriza-se pelo domínio de percepções individuais, enquanto que na visão objetivista nomotética, utiliza-se a operacionalização e construção de medidas, além de análises quantitativas.

Antes da primeira metade do século XX, havia pesquisadores e profissionais "práticos" que se baseavam nas experiências do dia-a-dia para moldar a tomada de decisão de gestores e investidores. Entretanto, os resultados e as experiências descritas por eles não eram tratados como sendo universalmente aplicáveis, permitindo classificar a abordagem dessa época como sendo uma aproximação positivista, numa tentativa de explicar por que as coisas são como elas são, mas com baixo poder de generalização dos resultados e das conclusões (MRAMOR; LONÈARSKI, 2002).

Naquela época, os pesquisadores construíam classes de regras de tomada de decisão financeira. A regra principal naquele tempo e que permanece até os dias atuais é a eventual compra de ativos subavaliados e, consequentemente, venda de ativos sobreavaliados, para a obtenção de ganhos. Nesse caso, o desafio é saber quando há subavaliação e sobreavaliação de ativos no mercado. A busca pelo lucro sobressai a qualquer outro objetivo. 
Quadro 1 Dimensões acerca das pressuposições sobre a natureza das ciências sociais.

\begin{tabular}{|c|c|c|}
\hline $\begin{array}{l}\text { Abordagem subjetivista } \\
\text { das ciências sociais }\end{array}$ & $\begin{array}{l}\text { Dimensões } \\
\text { subjetivas/ } \\
\text { objetivas }\end{array}$ & $\begin{array}{l}\text { Abordagem objetivista } \\
\text { das ciências sociais }\end{array}$ \\
\hline $\begin{array}{l}\text { Nominalismo: a realidade } \\
\text { é interpretada centrada no } \\
\text { indivíduo, sendo construída } \\
\text { socialmente. }\end{array}$ & Ontologia & $\begin{array}{l}\text { Realismo: a realidade é externa } \\
\text { ao indivíduo, ela é "dada”. }\end{array}$ \\
\hline $\begin{array}{l}\text { Antipositivismo: o conheci- } \\
\text { mento é relativo. Os investi- } \\
\text { gadores focalizam no signifi- } \\
\text { cado e examinam a totalida- } \\
\text { de de uma situação. }\end{array}$ & Epistemologia & $\begin{array}{l}\text { Positivismo: o conhecimento } \\
\text { científico é o mais verdadeiro. } \\
\text { Os investigadores focalizam nas } \\
\text { evidências empíricas, procuran- } \\
\text { do leis fundamentais e relacio- } \\
\text { namento causal }\end{array}$ \\
\hline $\begin{array}{l}\text { Voluntarismo: os seres hu- } \\
\text { manos possuem a vontade } \\
\text { livre e têm autonomia para } \\
\text { tomar decisões: livre-arbítrio. }\end{array}$ & $\begin{array}{l}\text { Natureza } \\
\text { Humana }\end{array}$ & $\begin{array}{l}\text { Determinismo: os seres hu- } \\
\text { manos são produtos de seus } \\
\text { ambientes. }\end{array}$ \\
\hline $\begin{array}{l}\text { Ideográfico: a compreensão } \\
\text { do mundo é feita por meio } \\
\text { de percepções e de acordo } \\
\text { com uma situação ou um } \\
\text { fenômeno. }\end{array}$ & Metodologia & $\begin{array}{l}\text { Nomotético: a compreensão } \\
\text { do mundo é feita por meio da } \\
\text { operacionalização e construção } \\
\text { de medidas que, junto com téc- } \\
\text { nicas de análises quantitativas, } \\
\text { procuram descobrir leis univer- } \\
\text { sais que explicam a realidade. }\end{array}$ \\
\hline
\end{tabular}

Fonte: adaptado de Burrell e Morgan (1979).

Havia a convicção de que as empresas possuíam alguma capacidade de endividamento "normal", que levaria a uma redução do custo médio do capital, com base nas características das empresas (ARDALAN, 2017). Contudo, essa capacidade de endividamento não era possível de ser determinada e, se existia, era com base nas experiências e sentimentos de gestores internos das companhias. Não 
se assumia nenhum tipo de comportamento racional e universalmente aplicável, a abordagem era positiva em sua natureza, baseada em "regras de ouro", limitadas ao ambiente e tempo da época (MRAMOR; LONĖARSKI, 2002).

Antes da década de 1950, a grande maioria das pesquisas em finanças era descritiva e em ambiente institucional bastante restrito. A partir dos anos cinquenta e sessenta, o homo economicus, indivíduo maximizador racional de utilidade, tornou-se o foco das proposições de como os seres humanos tomam decisões, dominando os estudos em finanças a partir de Markowitz (1952) e a teoria do portfólio; Modigliani e Miller (1958) e suas hipóteses de irrelevância da estrutura de capital e da política de dividendos; Sharpe (1964) e o Capital Asset Pricing Model (CAPM); e Black e Scholes (1973) e o modelo de apreçamento de opções. No caso das Finanças Corporativas, o estudo de Modigliani e Miller (1958) representa a mudança de paradigma em finanças de acordo com McGoun (1992, pp.166-167); além dos influentes trabalhos de Markowitz (1952), Kendall (1953), Sharpe (1964) e Fama (1965) que deram propulsão para essa mudança.

O Quadro 2 apresenta os paradigmas sociológicos de acordo com o modelo proposto por Burrell e Morgan (1979). As dimensões aqui são duas, a sociologia da mudança radical e a sociologia da regulação, que passam pela oposição entre objetividade e subjetividade, resultando em um diagrama com quatro paradigmas: humanista radical, estruturalista radical, interpretativista e funcionalista. Ardalan (2008) considera que a pesquisa em finanças passou de um paradigma interpretativista para o então funcionalista. No atual paradigma dominante (funcionalista), o mundo financeiro é um lugar de realidade concreta, o ser humano desempenha um papel passivo no qual o seu comportamento é fruto do ambiente em que está inserido (BURRELL; MORGAN, 1979).

O argumento central de todo o arcabouço teórico da Moderna Teoria em Finanças foi construído assumindo que os indivíduos são seres racionais, dentro de uma interpretação funcionalista. Contudo, com tantas anomalias e crises financeiras acontecendo, pesquisadores e especialistas começaram a se questionar quanto à validade desse pressuposto econômico (ZANALDA, 2015; ARDALAN, 2008; KAHNEMAN; TVERSKY, 1979). Será que as hipóteses e os pressupostos utilizados por tanto tempo estão contidos na realidade? Aproximar as finanças cada vez mais de uma realidade não separada da mente dos indivíduos parece ser um grande desafio. 
Quadro 2 Diagrama dos paradigmas sociológicos.

\section{Sociologia da mudança radical}

Preocupação com problemas de mudança, conflito e coerção nas estruturas sociais, enfatizando divisão, hostilidade, dissenso e desintegração.

Subjetivo

$\begin{array}{ccc}\text { Humanista radical } & \text { Estruturalista radical } & \text { Objetivo } \\ \text { Interpretativista } & \text { Funcionalista } & \end{array}$

Equilíbrio social enfatizando compromisso, coesão, solidariedade, consenso, reciprocidade, cooperação, integração, estabilidade e persistência.

\section{Sociologia da regulação}

Fonte: adaptado de Burrell e Morgan (1979).

A crítica da pós-modernidade em Finanças acusa as pesquisas de serem performativas demais, com grande potencial para alterar seus objetos de estudo (ARDALAN, 2017; ARDALAN, 2008). A busca por suposições mais realistas vem se apresentando em pesquisas que reconhece o ser humano não apenas como um maximizador mecânico de riqueza, mas sim como um indivíduo muito mais complexo. Além do mundo acadêmico, pessoas não especialistas e profissionais de finanças, que parecem acreditar que a racionalidade é um bom modo de descrever indivíduos, sociedades e mercados, sentem-se bem diferentes quando lhes são questionados com perguntas específicas sobre pessoas e instituições que eles conhecem bem: na prática, a teoria tende a não funcionar (ARDALAN, 2017; BAKER; RICCIARDI, 2014; BAKER; WURGLER, 2002).

Na década de 1970, uma corrente ou paradigma alternativo, menos funcionalista e linear, surgiu ao criticar a racionalidade ilimitada e ao incorporar aspectos comportamentais nas decisões de financiamento e investimento. A chamada "finanças comportamentais" propõe uma reaproximação da área com o paradigma interpretativo. As finanças comportamentais surgiram com o crescimento de estudos psicológicos experimentais em contextos econômico-financeiros. A partir desses estudos, o argumento central quanto à racionalidade do investidor foi questionado e, consequentemente, os modelos do paradigma dominante, com base no homo economicus e no indivíduo maximizador racional de utilidade, passaram a ser aperfeiçoados. 
Os fundamentos das finanças comportamentais encontram-se centrados decisivamente nos trabalhos de dois psicólogos e pesquisadores israelenses: Amos Tversky e Daniel Kahneman (1974; 1979). Mesmo não sendo economista, Daniel Kahneman foi congratulado com o The Prize in Economic Sciences em 2002, o Prêmio Nobel de Economia. Mais recente, em 2017, o pesquisador e economista Richard Thaler também ganhou o Prêmio Nobel de Economia por contribuições na área de finanças comportamentais. Para Thaler (2018), a racionalidade limitada, as preferências sociais e a falta de autocontrole afetam as decisões de financiamento e investimento dos indivíduos, assim como os resultados do mercado.

Para as finanças comportamentais, o indivíduo racional toma sua decisão de uma forma razoável de acordo com a sua capacidade computacional e o conhecimento disponível (ARDALAN, 2017; PONDÉ, 2014). Neste contexto de racionalidade limitada, há um ambiente complexo em relação à capacidade mental do indivíduo, onde crenças e preferências limitam as decisões puramente racionais: vieses, regras de bolso, aversão a perdas, contabilidade mental (THALER, 2018; KAHNEMAN; TVERSKY, 1979). Dessa forma, não é possível considerar todas as alternativas e, muito menos, todas as consequências de uma decisão. O Quadro 3 apresenta alguns vieses comportamentais que podem alterar as percepções dos indivíduos e, consequentemente, influenciar as suas decisões.

Quadro 3 Vieses comportamentais que podem alterar as percepções dos indivíduos.

\section{Pontos de referência e aversão a perdas}

Efeito dotação: sobrevaloriza-se um bem que já possui, em comparação a outro bem que ainda não possui.

Viés do status quo: percebe-se mais a possível perda que o possível ganho, em relação à situação atual.

Efeito house money: novos ricos não são avessos ao risco.

\section{Excesso de confiança}

Confiança excessiva em relação à acuracidade da informação privilegiada.

llusão do conhecimento: confiança crescente a partir de informações parciais. llusão do controle: crença infundada na capacidade de influenciar eventos. 


\section{Erros estatísticos}

Falácia do apostador: necessidade de se observar padrões quando, na realidade, eles inexistem.

Eventos muito raros têm as suas probabilidades calculadas com muito erro (tanto para cima como para baixo).

Paradoxo de Ellsberg: diferenças na compreensão de risco e de incerteza.

Viés da extrapolação: falha na correção da regressão com relação à média e ao tamanho da amostra.

Peso excessivo atribuído em função de experiências passadas em detrimento de estatísticas de grandes amostras.

Sobrerreação: peso excessivo atribuído a eventos recentes.

Falha no ajustamento das probabilidades.

\section{Outros vieses comportamentais}

Pensamento "mágico": crença na habilidade de ser capaz de influenciar resultados, quando não é possível.

Inconsistência dinâmica: taxas de desconto negativas, aversão à dívida.

Percepção seletiva e efeito manada.

Autocontrole insuficiente.

Viés de familiaridade: tendência em investir em ativos conhecidos e que estão próximos.

Facilidade de lembrança de determinados eventos.

Dissonância cognitiva e minimização do arrependimento (armadilha da confirmação).

Efeito disjunção: esperar por informações novas mesmo quando não são importantes para a tomada de decisão.

Ancoragem e vieses de framing.

Tendência a apostar e assumir riscos desnecessários em algumas situações.

Contabilidade mental e compartimentalização.

Fonte: adaptado de Rubinstein (2001).

A abordagem comportamental em finanças aparece em duas vertentes. A primeira é baseada na economia comportamental mais formal desenvolvida por Kah- 
neman e Tversky (1979) e a segunda refere-se a estudos já na área corporativa. Por exemplo, no contexto das finanças corporativas, Baker e Wurgler (2002) assumem certa irracionalidade temporária dos investidores na construção da teoria de market timing, muito devido ao otimismo criado por eles diante das decisões financeiras e de novas informações da companhia. Do lado dos gestores, a elevada expectativa e pressão do ambiente empresarial podem fazê-los agir irracionalmente (KRIEGER; ANG, 2013; ZHANG; GIMENO, 2016).

No Brasil, apesar do acentuado crescimento de pesquisas sobre o tema nos últimos anos, a grande maioria ainda é voltada em replicar os estudos seminais como o de Kahneman e Tversky (1979) em estudantes universitários (BARRETO; MACEDO; ALVES, 2013; MARTINS et al., 2015; TORGA et al., 2018). Contudo, também há trabalhos que analisam vieses cognitivos e heurísticos na tomada de decisão de agentes econômicos como gestores e investidores (YOSHINAGA; RAMALHO, 2014; AGUIAR et al. 2016; SILVA et al., 2017). Os resultados suportam as evidências de que os indivíduos são influenciados pelos seus vieses comportamentais no processo de tomada de decisão.

De fato, as finanças comportamentais podem preencher lacunas importantes das finanças empresariais. Por existir estratégias corporativas que exploram os vieses comportamentais, de negociações à emissão de títulos de longo prazo, a união dessas visões fornece uma melhor compreensão de algumas ações aparentemente não racionais de agentes econômicos como gestores e investidores. Uma vez que existem esses vieses cognitivos, agentes disciplinados podem desenvolver maneiras de evitar cometer comportamentos prejudiciais, ou, entre os gestores que não possuem autoconhecimento suficiente para evitá-los, cabe aos seus superiores a responsabilidade de intervir e restringir as decisões daqueles.

O importante para alunos, pesquisadores e demais indivíduos interessados na investigação teórica e prática em Finanças, é saber que essas duas abordagens não nasceram do mesmo ninho paradigmático, ou seja, seus postulados e processos epistemológicos são diferentes, o que também não quer dizer que elas não se conversam, pelo contrário, uma tem muito a contribuir com a outra e vice-versa. 


\section{Notas de Ensino}

\section{RESUMO DO CASO}

Quando o Sr. Batista fez seu primeiro sapato ele não poderia imaginar que anos mais tarde as suas confecções seriam referências nacionais. Da necessidade de se ter calçados mais resistentes para aguentar a jornada de trabalho, juntada à paixão de produzir seus próprios sapatos, o Sr. Batista tomou a decisão de empreender e, assim, deu início à sua empresa. Contudo, com o crescimento e com a maior complexidade do negócio, as decisões empresariais passaram a exigir cada vez mais de seu dono. O presente caso mostra como as crenças, emoções e sentimentos do Sr. Batista influenciaram as suas decisões e, consequentemente, levaram ao sucesso de sua empresa.

\section{OBJETIVOS EDUCACIONAIS}

O caso tem como objetivo educacional promover reflexões a respeito da complexidade do processo de tomada de decisões financeiras no contexto empresarial, tendo em conta as influências cognitivas, sociais e emocionais observadas sobre a tomada de decisão. Juntamente com isso, este caso de ensino fornece a possibilidade de discussão sobre questões epistemológicas e paradigmáticas em Finanças.

\section{ASPECTOS PEDAGÓGICOS}

Este caso foi desenvolvido para aplicação em cursos de graduação e pós-graduação em Gestão, Gestão Financeira, Administração, Ciências Contábeis, Economia e demais cursos com disciplinas na área de Finanças. O caso em questão tem como indivíduos alvos pesquisadores, estudantes de pós-graduação e estudantes de graduação em nível avançado. A narrativa do presente caso é fictícia, contudo, a construção do mesmo foi baseada nas experiências acadêmicas e profissionais dos autores. Por se tratar de uma temática importante dentro do processo de conhecimento em Finanças, o caso foi aplicado em sala de aula previamente à sua publicação e os resultados foram positivos.

O professor que for fazer uso deste caso pode achar necessário adaptar o mesmo para alcançar algum objetivo específico. Devido à modalidade de ensino 
ou ao tamanho da turma, sugere-se como organização da aplicação os seguintes procedimentos: (a) leitura e análise individual realizada pelos alunos (30 minutos); (b) análise e discussão dos alunos em pequenos grupos ou de forma individual, orquestrada pelo professor (40 minutos); (c) fechamento da discussão pelo professor, no qual o caso é analisado fazendo conexão com a literatura e tecendo as considerações finais (30 minutos).

De forma a estimular ainda mais o debate em sala de aula, o professor pode perguntar aos alunos se eles conhecem ou já ouviram falar de gestores parecidos com o Sr. Batista, com questões relacionadas à complexidade do processo de tomada de decisão no contexto empresarial. Provavelmente, os alunos já se depararam com pessoas que lembram o indivíduo do caso, seja no ambiente de trabalho, em meio a amizades (algum colega gestor de empresa familiar) ou até mesmo pela mídia. Quando os alunos são questionados com perguntas específicas sobre pessoas e instituições que eles conhecem bem, mesmo aqueles que acreditam que o homo economicus define bem os indivíduos e a sociedade atual, sentem-se com a pulga atrás da orelha por se esbarrarem com uma realidade mais complexa.

Para os alunos que quiserem aprofundar nessas questões epistemológicas e paradigmáticas em Finanças, ou se interessarem por finanças corporativas ou finanças comportamentais, as referências bibliográficas encontradas no final deste documento fornecem ótimas leituras, indo desde artigos com pesquisas empíricas a livros textos mais teóricos. Se o professor preferir, pode pedir a leitura prévia de algum deles, como a obra de Ardalan (2008) ou Simon (2013).

\section{Questões para Discussão}

De forma a estimular o debate em sala de aula, o presente caso de ensino propõe cinco questões para discussão, no entanto, outros questionamentos podem ser formulados pelo professor ou surgir durante a leitura do caso pelos participantes. As questões contemplam os objetivos do caso de ensino, podendo ser respondidas com base nas informações apresentadas nele, como também questões subjacentes que fazem conexão com a literatura. A sugestão é que o professor trabalhe 
essas questões sem apresentar a discussão que vem em seguida, o objetivo é que, em um ambiente de reflexão e discussão, os leitores do caso consigam conectar o mesmo com a literatura, em uma visão crítica e reflexiva. Depois disso, o professor pode apresentar a discussão proposta aqui, a fim de verificar a proximidade do debate realizado em sala com a discussão proposta por este estudo, levantando e fechando pontos importantes ainda não levantados em sala de aula.

- Questão 1 Quais aspectos mais influenciaram as decisões da empresa do Sr. Batista?

- Questão 2 Quais as características do indivíduo das finanças comportamentais? O Sr. Batista apresenta essas características?

- Questão 3 Quais as principais diferenças entre as finanças comportamentais e as finanças corporativas?

- Questão 4 Pense no horizonte de tempo de vida da empresa do Sr. Batista. Até quando a empresa irá durar? Há dificuldade na conciliação de interesses de curto e longo prazo?

- Questão 5 Na sua percepção, quais são as maiores contribuições das finanças comportamentais? E qual a sua crítica quanto a essa abordagem?

\section{Discussão: Análise do Caso e Conexão com a Literatura}

Questão 1 Quais aspectos mais influenciaram as decisões da empresa do Sr. Batista?

A partir da história do Sr. Batista e de sua empresa, é possível notar claramente que as decisões tomadas por ele são influenciadas pelas suas crenças, emo- 
ções e sentimentos, ou seja, por aspectos comportamentais. Portanto, o Sr. Batista é um ser muito mais complexo do que apenas um mero maximizador de riqueza "racional", e é impossível entender sua empresa sem considerá-lo, ao passo que a empresa seria totalmente diferente sem ele.

Esses vieses comportamentais que influenciam as decisões do Sr. Batista aparecem no texto em momentos de negociação e tomada de decisão de financiamento e investimento. Importante ressaltar que a negociação apresenta papel vital em alguns dos eventos empresariais mais importantes: aquisições e fusões, busca por novos financiamentos bancários, contratos de fornecedores e clientes, negociação com sindicato e empregados. Quando o Sr. Batista nem considera fazer uso de uma linha de crédito por não conhecer a instituição financeira, e por já ter um banco com um gerente que o acompanha há anos, isso é reflexo dos sentimentos de familiaridade, conforto e confiança, por exemplo.

Questão 2 Quais as características do indivíduo das finanças comportamentais? O Sr. Batista apresenta essas características?

As finanças comportamentais consideram um indivíduo complexo e seus vieses cognitivos no processo de tomada de decisão. Dessa forma, crenças, emoções e sentimentos podem levar a decisões não racionais ou não maximizadoras de riqueza, ou ainda, os vieses cognitivos podem levar a anomalias (THALER, 2018). O Sr. Batista se enquadra totalmente nessa abordagem. Ele tem um sentimento pela fabricação de sapatos de difícil mensuração, faz questão de participar ou estar próximo de todo o processo de fabricação, preocupa-se com a qualidade de seus produtos e mantém boa relação com clientes, fornecedores e funcionários. O Sr. Batista toma decisões de maneira a manter esse status quo. Essas características individuais são algumas das consideradas pelas finanças comportamentais.

Questão 3 Quais as principais diferenças entre as finanças comportamentais e as finanças corporativas?

Os modelos econômicos utilizados pelas finanças corporativas foram trazidos da abordagem econômica neoclássica e baseiam-se sobre uma série de pre- 
missas (axiomas) de que os comportamentos humanos apresentariam racionalidade ilimitada. Em relação ao caso, a epistemologia a qual se solidificou o paradigma dominante sobre a discussão das decisões de financiamento e investimento da pouco valor às emoções e aos sentimentos do Sr. Batista. Isso cria limitações ou um problema ontológico de coisas que precisam existir ou de condições que precisam ser preenchidas para a validação do processo que transforma intuição/percepção em conhecimento.

Se as pessoas fossem criaturas $100 \%$ racionais, então só seria preciso dar a elas as informações necessárias para que tomassem boas decisões, e elas imediatamente tomariam as decisões certas. Contudo, a capacidade de raciocínio, a percepção e o tempo limitado, muitas vezes, levam a análises simplistas e a decisões errôneas do ponto de vista econômico-racional. Se os princípios que moldam o comportamento em torno da tomada de decisão do Sr. Batista forem os mesmos princípios que moldam o comportamento de outros gestores de empresas, mesmo sendo diferente o conjunto de emoções e sentimentos de cada um, essas características precisam ser consideradas para um melhor entendimento da tomada de decisão empresarial.

As finanças comportamentais têm como meta explicar e prever a tomada de decisão do indivíduo e os fluxos financeiros decorrentes a partir de pressupostos psicologicamente mais realistas, sem depender das (rígidas) premissas usadas nas finanças corporativas. A principal diferença é que as finanças comportamentais assumem a racionalidade limitada, mostrando que a psicologia tem papel importante. As finanças comportamentais consideram um indivíduo complexo e seus vieses cognitivos, sociais e emocionais no processo de tomada de decisão, diferentemente das finanças corporativas.

Questão 4 Pense no horizonte de tempo de vida da empresa do Sr. Batista. Até quando a empresa irá durar? Há dificuldade na conciliação de interesses de curto e longo prazo?

A concepção de tempo do Sr. Batista é a sua própria existência, não existindo "tempo" após a sua morte. Assim, a empresa também fica limitada a esse horizonte e isso deve ser considerado no entendimento dela e na tentativa de pre- 
visões futuras. Ou seja, podem-se propor premissas e fazer inferências que só serão válidas enquanto o Sr. Batista viver, pode ser que depois da morte dele, para entender a empresa, seja necessário compreender o Sr. Silva ou o Sr. Manoel ou a Sra. Carmem, quem é que esteja à frente das decisões da empresa criada pelo Sr. Batista.

É importante essa questão da percepção de tempo porque, normalmente, as companhias são olhadas sob o princípio da continuidade, ou seja, assume-se que elas continuarão em operação no futuro. Contudo, as finanças comportamentais consideram a percepção seletiva um autocontrole insuficiente na tomada de decisão do indivíduo quanto ao horizonte de tempo, ou seja, há uma dificuldade em alinhar decisão de curto prazo e longo prazo. Por exemplo, a abertura de capital da empresa do Sr. Batista poderia ser uma boa decisão para o futuro da companhia, no entanto, o Sr. Batista preferiu manter o seu modelo de gestão e controle do negócio.

Questão $5 \mathrm{Na}$ sua percepção, quais são as maiores contribuições das finanças comportamentais? E qual a sua crítica quanto a essa abordagem?

A aproximação que as finanças comportamentais fizeram da economia com a psicologia trouxe contribuições significantes para a área no geral. As contribuições das finanças comportamentais vêm crescendo e ganhando representatividade. O olhar descritivo sobre o comportamento das pessoas mostra que elas se comportam de forma diferente, condicionadas ao cenário da tomada de decisão e ao contexto multifatorial. As finanças comportamentais chamam a atenção para o reconhecimento das limitações sociais, cognitivas e emocionais dos indivíduos na projeção do ambiente econômico-financeiro. Entretanto, as finanças comportamentais têm suas limitações. Os próprios impactos psicológicos podem ser em si contraditórios, sendo que para toda anomalia que aconteça no mercado é possível encontrar um efeito psicológico responsável. Porém, os pesquisadores e profissionais em finanças estão cada vez mais interessados em entender o indivíduo complexo tomador de decisões, e isso vai além da empresa, é o caso do Sr. Batista e o entendimento de sua complexidade. 


\section{Considerações Finais}

A construção de conhecimento da chamada Moderna Teoria de Finanças tem como pressuposto principal o da racionalidade do indivíduo. Depois de décadas de prevalência do homo economicus em pesquisas da área, uma nova abordagem vem ganhando força para explicação de problemas financeiros. As finanças comportamentais têm ganhado espaço para contribuições que relaxem pressupostos do paradigma dominante, comumente empregados nas finanças corporativas, como a irracionalidade do investidor ou a ineficiência de mercado.

Abordagens que consideram um ser humano multifacetado em um ambiente dinâmico e complexo são positivas, contudo, não universais. O consenso da importância do relaxamento de alguns fortes pressupostos que dominaram o paradigma dominante por décadas e a necessidade de novas correntes teóricas deixam um caminho incerto para onde caminharão as pesquisas em finanças. $A$ oscilação histórica entre os paradigmas funcionalista e interpretativo de Burrell e Morgan (1979) deixa dúvidas se as finanças comportamentais se figurarão como uma corrente dentro do paradigma funcionalista ou se terá forças para superar o paradigma dominante.

O certo é que este contexto representa um convite para pesquisadores e profissionais que buscam contribuir com conhecimento em finanças e melhor compreender os fenômenos da área. O pesquisador precisa estar ciente das perspectivas paradigmáticas, trabalhar em harmonia com o ambiente, engajar com os diversos participantes do mercado, levando a uma maior percepção e compreensão dos fatos, não ignorando as complexidades do contexto. O profissional de finanças precisa acrescentar pesos e ponderações não universais na tomada de decisão empresarial, não desconsiderar o Sr. Batista, por exemplo; deixar o livro de receitas de lado, sem foco demasiado nas consequências que seguem às decisões financeiras. Neste caso, o comportamento de um indivíduo "complexo" é levado em conta, considerando um determinado ambiente e tempo. Avança-se no interpretativismo, predominantemente descritivo, para depois avançar no teórico funcionalista. 


\section{Referências}

AGUIAR, E. S. et al. A Influência de Gênero, Idade, Formação e Experiência nas Decisões de Investimentos: uma Análise do Efeito Confiança. Revista Evidenciação Contábil \& Finanças, v. 4, n. 3, p. 44-55, 2016. http://dx.doi.org/10.18405/recfin20160303

ARDALAN, K. Capital structure theory: Reconsidered. Research in International Business and Finance, v. 39, Part B, p. 696-710, 2017. https://doi.org/10.1016/j.ribaf.2015.11.010

ARDALAN, K. On the role of paradigms in finance. New York: Ashgate, 2008.

ÁVILA, L. A. C. et al. Behavioral Biases in Investors' Decision: Studies Review from 2006-2015. Revista de Gestão, Finanças e Contabilidade, v. 6, n. 2, p. 112-131, 2016. https://doi.org/10.18028/2238-5320/ rgfc.v6n2p112-131

BAKER, H. K.; RICCIARDI, V. How Biases Affect Investor Behaviour. The European Financial Review, February-March, p. 7-10, 2014. Disponível em SSRN: https://papers.ssrn.com/sol3/papers.cfm?abstract_id $=2457425$

BAKER, M.; WURGLER, J. Market timing and capital structure. The Journal of Finance, v. 57, n. 1, p. 1-32, 2002. https://doi.org/10.1111/1540-6261.00414

BARRETO, P. S.; MACEDO, M. A. S; ALVES, F. J. S. Tomada de Decisão e Teoria dos Prospectos em Ambiente Contábil: Uma Análise com Foco no Efeito Framing. Revista de Gestão, Finanças e Contabilidade, v. 3, n. 2, p. 61-79, 2013.

BLACK, F.; SCHOLES, M. The pricing of options and corporate liabilities. Journal of Political Economy, v. 81, n. 3, p. 637-654, 1973. Recuperado de http://www.jstor.org/stable/1831029

BURRELL, G.; MORGAN, G. Sociological paradigms and organizational analysis. London: Heinemann Educational Books, 1979.

FAMA, E. The behavior of stock-market prices. Journal of Business, v. 38, n. 1, p. 34-105, 1965. Recuperado de http://www.jstor.org/stable/2350752

KAHNEMAN, D.; TVERSKY, A. Prospect Theory: an analysis of decisions under risk. Econometrica, v. 47, n. 2, p. 263-291, 1979. Recuperado de http://www.jstor.org/stable/1914185

KENDALL, M. G. The analysis of economic time series. Journal of the Royal Statistical Society, v. 96, p. 11-25, 1953. Recuperado de http://www.jstor.org/stable/2980947

KRIEGER, K.; ANG, J. S. The Unintended Consequences of High Expectations and Pressure on New CEOs. Journal of Business Finance \& Accounting, v. 40, n. 3-4, p. 501-526, 2013. https://doi.org/10.1111/ jbfa.12021

MALAQUIAS, R. F.; MAMEDE, S. P. N. Efeito Calendário e Finanças Comportamentais no Segmento de Fundos Multimercados. RAC - Revista de Administração Contemporânea, v. 19, n. spe, p. 98-116, 2015. http://dx.doi.org/10.1590/1982-7849rac20152062

MARKOWITZ, H. Portfolio selection. The Journal of Finance, v. 7, n. 1, p. 77-91, 1952. https://doi.org/10.1111/j.1540-6261.1952.tb01525.x

MARTINS, J. F. et al. O comportamento financeiro dos estudantes de graduação à luz da teoria dos prospectos. Revista Ciências Administrativas, v. 21, n. 1, p. 95-111, 2015. http://dx.doi.org/10.5020/23180722.2015.v21n1p95 
A Tomada de Decisão Empresarial em Finanças: Aspectos Epistemológicos e Paradigmáticos Business Decision-making in Finance: Epistemological and Paradigmatic Aspects

Matheus da Costa Gomes | Mauricio Ribeiro do Valle

MCGOUN, E. G. On knowledge of finance. International Review of Financial Analysis, v. 1, n. 3, p. 161177, 1992. https://doi.org/10.1016/1057-5219(92)90002-L

MODIGLIANI, F. E.; MILLER, M. H. The cost of capital, corporation finance, and the theory of investment. The American Economic Review, v. 48, n. 3, p. 261-97, 1958. Recuperado de http://www.jstor.org/stable/1809766

MRAMOR, D.; LONČARSKI, I. Traditional, modern and new approach to finance. Conference on alternative perspectives on finance. University of Hamburg, Hamburg, Germany, 6, August 2002.

PONDÉ, J. L. Racionalidade, incomensurabilidade e história: aprendendo com um diálogo entre as obras de HA Simon e TS Kuhn [Discussion Paper]. Instituto de Economia, Universidade Federal do Rio de Janeiro, 2014. Recuperado de http://www.ie.ufrj.br/images/pesquisa/publicacoes/discussao/2014/TD_ IE_010_2014_-_Ponde.pdf.

RUBINSTEIN, M. Rational Markets: Yes or No? The Afirmative Case. Financial Analysts Journal. v. 28, n. 1, 2001. https://doi.org/10.2469/faj.v57.n3.2447

ROSTAMI, M.; DEHAGHANI, Z. A. Impact of Behavioral Biases (overconfidence, ambiguity-aversion and loss-aversion) on Investment Making Decision in Tehran Stock Exchange. Journal of Scientific Research and Development, v. 2, n. 4, p. 60-64, 2015.

SHARPE, W. F. Capital asset prices: a theory of market equilibrium under conditions of risk. The Journal of Finance, v. 19, n. 3, p. 425-442, 1964. http://www.jstor.org/stable/2977928

SILVA, P. V. J. G.; SANTOS, J. B. ; PEREIRA, G. P. Estudo Bibliométrico sobre Finanças Comportamentais no Brasil de 2007 a 2017. In: 5th Brazilian Behavioral Economics and Finance Meeting, Fundação Getulio Vargas, São Paulo, 2018. https://cef.fgv.br/sites/cef.fgv.br/files/arquivos/2._artigo_bibliometria_ fin._comp_-_final.pdf

SILVA, T. B. J. et al. Influência do Excesso de Confiança e Otimismo no Endividamento de Organizações Cinquentenárias e não Cinquentenárias Brasileiras. Revista Evidenciação Contábil \& Finanças, v. 5, n. 2, p. 1-3, 2017. http://dx.doi.org/10.18405/recfin20170203

SIMON, H. A. Administrative behavior: a study of decision-making processes in administrative organizations. 4th ed. New York: Simon \& Schuster, 2013.

THALER, R. H. From Cashews to Nudges: The Evolution of Behavioral Economics. American Economic Review, v. 108, n. 6, p. 1265-1287, 2018. https://doi.org/10.1257/aer.108.6.1265

TORGA, E. M. M. F. et al. Behavioral finance and games: simulations in the academic environment. Revista Contabilidade \& Finanças, v. 29, n. 77, p. 297-311, 2018. http://dx.doi.org/10.1590/1808-057x201804830 TVERSKY, A.; KAHNEMAN, D. Judgment under uncertainty: heuristics and biases. Science, v. 185, n. 4157, p. 1124-1131, 1974. http://www.jstor.org/stable/1738360

YOSHINAGA, C. E.; RAMALHO, T. B. Finanças Comportamentais no Brasil: uma aplicação da teoria da perspectiva em potenciais investidores. Revista Brasileira de Gestão de Negócios, v. 16, n. 53, p. 594615, 2014. http://dx.doi.org/10.7819/rbgn.v16i52.1865

ZANALDA, G. Financial Crises, History of. International Encyclopedia of the Social \& Behavioral Sciences (Second Edition), p. 183-190, 2015. https://doi.org/10.1016/B978-0-08-097086-8.71074-9

ZHANG, Y.; GIMENO, J. Earnings Pressure and Long-Term Corporate Governance: Can Long-Term-Oriented Investors and Managers Reduce the Quarterly Earnings Obsession? Organization Science, v. 27, n. 2, p. 354-372, 2016. https://doi.org/10.1287/orsc.2016.1056 